\title{
National Perspectives on the Training of Neurosurgery Residents in Stereotactic Radiosurgery
}

\author{
Alireza Mansouri, Christopher D. Witiw, Jetan H. Badhiwala, Farshad Nassiri, \\ Patrick J. McDonald, Abhaya V. Kulkarni, Gelareh Zadeh, Douglas Kondziolka
}

\begin{abstract}
Background: Despite the critical role played by neurosurgeons in performing radiosurgery, neurosurgery residents in Canada have limited exposure to radiosurgery during their training. A survey of neurosurgery residents and faculty along with radiation oncology faculty was conducted to analyze perspectives regarding incorporating formal radiosurgery training into the neurosurgery residency curriculum Methods: An online survey platform was employed. Descriptive statistics were used to summarize center and respondent characteristics. Categorical variables were compared using odds ratios and corresponding 95\% confidence intervals. The chisquared test was utilized to assess statistical significance. A value of $p<0.05$ was considered significant Results: The response rate was $31 \%$ (119/381); 87\% (102/119) of respondents were from the neurosurgical specialty and 13\% (17/119) from radiation oncology. Some $46 \%$ of residents (18/40) were "very uncomfortable" with radiosurgery techniques, and $57 \%$ of faculty (42/73) believed that dedicated radiosurgery training would be beneficial though impractical. No respondents felt that "no training" would be beneficial. A total of $46 \%$ of residents (19/41) felt that this training would be beneficial and that time should be taken away from other rotations, if needed, while $58 \%$ of faculty (42/73) and 75\% (28/41) of residents believed that either 1 or 1-3 months of time dedicated to training in radiosurgery would suffice Conclusions: Canadian neurosurgeons are actively involved in radiosurgery. Despite residents anticipating a greater role for radiosurgery in their future, they are uncomfortable with the practice. With the indications for radiosurgery expanding, this training gap can have serious adverse consequences for patients. Considerations regarding the incorporation and optimal duration of dedicated radiosurgery training into the Canadian neurosurgery residency curriculum are necessary.
\end{abstract}

RÉSUMÉ: Perspectives nationales concernant la formation en radiochirurgie stéréotaxique des résidents en neurochirurgie. Contexte : Malgré le rôle crucial que jouent les neurochirurgiens lors de la radiochirurgie, les résidents en neurochirurgie au Canada n'ont qu'une expérience limitée en radiochirurgie pendant leur formation. Nous avons effectué une enquête auprès des résidents et du corps professoral de neurochirurgie ainsi que du corps professoral de radio-oncologie afin d'examiner leurs perspectives concernant l'intégration d'une formation officielle en radiochirurgie au curriculum de la résidence en neurochirurgie. Méthodologie : Nous avons utilisé une plateforme d'enquête en ligne pour effectuer l'enquête. Nous avons eu recours à des méthodes statistiques descriptives pour réaliser le sommaire des caractéristiques des centres et des répondants. Nous avons comparé les variables qualitatives au moyen de rapports de cote, avec des intervalles de confiance à $95 \%$. Le test du chi-carré a été utilisé pour évaluer la signification statistique. Une valeur de $\mathrm{p}<0,05$ était considérée comme significative au point de vue statistique. Résultats : Le taux de réponse a été de 31\% (119/381); 87\% (102/ 119) des répondants étaient en neurochirurgie et 13\% (17/119) étaient en radio-oncologie. Quarante-six pour cent des résidents (18/40) étaient « très inconfortables » avec les techniques radiochirurgicales et $57 \%$ du corps professoral (42/73) croyaient que la formation en radiochirurgie serait bénéfique mais irréalisable. Aucun répondant ne pensait qu'aucune formation serait bénéfique. Au total, $46 \%$ des résidents (19/41) estimaient que cette formation serait bénéfique et qu'au besoin, le temps de formation devrait être soustrait d'autres stages, alors que 58\% des membres du corps professoral (42/73) et $75 \%$ (28/41) des résidents croyaient que 1 mois ou de 1 à 3 mois de formation en radiochirurgie suffiraient. Conclusions : Les neurochirurgiens canadiens sont impliqués activement en radiochirurgie. Bien que les résidents anticipent que la radiochirurgie jouera un plus grand rôle à l'avenir, ils sont inconfortables avec la pratique de la radiochirurgie. Comme les indications de la radiochirurgie augmentent, cette lacune dans la formation des résidents peut avoir des conséquences négatives sérieuses pour les patients. Il est donc nécessaire de réfléchir à l'inclusion et à la durée optimale de la formation en radiochirurgie dans le curriculum de la résidence en neurochirurgie au Canada.

Keywords: Education, neurosurgery, radiosurgery, residency, survey

doi:10.1017/cjn.2016.314

Can J Neurol Sci. 2017; 44: 51-58

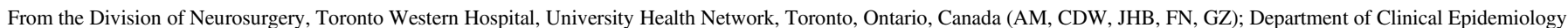

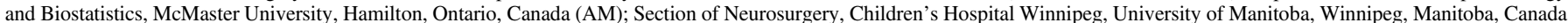

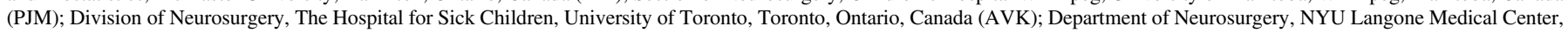

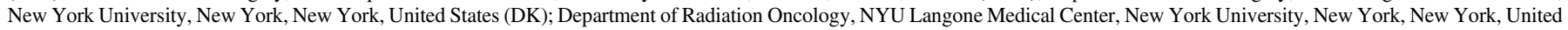
States (DK).

Received June 23, 2015. Final Revisions Submitted March 29, 2016. Date of Acceptance April 122016.

Correspondence to: Alireza Mansouri, Division of Neurosurgery, Toronto Western Hospital, 4W-436, 399 Bathurst Street, Toronto, Ontario M5T 2S8, Canada.

Email: alireza.mansouri@utoronto.ca. 


\section{INTRODUCTION}

Accumulating evidence over the past two decades has led to radiosurgery being considered a safe and efficacious tool for primary and/or adjuvant management of a variety of conditions. ${ }^{1-9}$ Patient care in the domain of radiosurgery is most optimally delivered through a multidisciplinary approach, involving collaboration among neurosurgeons, radiation oncologists and medical physicists. The indications for radiosurgery as a minimally invasive alternative to open craniotomy for a variety of intracranial pathologies have been expanding. In the United States, for example, the number of radiosurgery cases for many indications is surpassing that of craniotomies. ${ }^{10}$ While this pattern may not necessarily hold true for other nations, it is perhaps an indication of the direction that the specialty will take. Future neurosurgeons need to be aware of the intricacies of radiosurgery as part of the comprehensive management of patients. Thus, a strong foundation built on knowledge and skill is necessary.

The ideal residency training program is structured such that graduating trainees are fit for independent practice based on a consideration of the current best evidence and anticipation of the future landscape of the specialty. The indications for radiosurgery are expanding, and this shift in the treatment paradigm calls for a concurrent shift in the education and training of neurosurgery residents. In both the United States and Canada, a transition toward competency-based medical education is underway. ${ }^{11,12}$ As of 2012, the Accreditation Council for Graduate Medical Education (ACGME, United States, https://www.acgme.org) updated the requirements, mandating a minimum of 10 radiosurgery cases for neurosurgical residents. Although the Royal College of Physicians and Surgeons of Canada (RCPSC, Ottawa, Ontario, Canada) is seeking to transition to a competency-based approach to training, a formal approach toward radiosurgery training for neurosurgery residents has not been devised. This has the potential to affect the future delivery of comprehensive, safe and effective patient care.

Surveying practitioners in a particular field is one of the most commonly implemented strategies for developing the content and structure of competency-based medical curricula. ${ }^{13-15}$ In order to gain insight into the current and anticipated future practice of radiosurgery and training of neurosurgical residents across Canada, a nationwide survey of Canadian neurosurgery residents and faculty along with radiation oncology faculty involved in radiosurgery was conducted. Our primary objective was to gauge resident comfort regarding the indications and technical aspects of radiosurgery and to assess resident and faculty perspectives on the need for, and feasibility of, incorporating radiosurgery training into the Canadian neurosurgery resident curriculum.

\section{Methods}

\section{Survey Development}

The survey was designed and disseminated electronically using "Survey Monkey" (see Appendix I) to Canadian neurosurgical and radiation oncology faculty, along with neurosurgical residents/fellows (November 2014 to January 2015). The email list of neurosurgery contacts was obtained through the Canadian Neurological Sciences Federation. In addition, an email contact list of academic radiation oncologists was used to contact faculty from this specialty. The survey questions were designed to obtain an overall perspective on the demographics of the practice of radiosurgery across Canada. Although the exact duration of the rotation is not specified by the RCPSC for radiation oncologists, rotations pertaining to "neurologic cancers" are required. ${ }^{16}$ Therefore, our survey included radiation oncologists in order to gauge their perspective on whether additional training in radiosurgery for neurosurgeons would be beneficial. Questions potentially relevant to the scope of practice were developed and further vetted by the four senior authors, who are neurosurgeons with an active radiosurgery practice (AVK, PM, GZ and DK); AVK and PM are also active directors of neurosurgical residency programs in Canada. Please refer to Appendix I for a list of survey questions. Participation in the survey was taken as implied consent. All data were anonymized.

\section{Statistical Analysis}

Data were imported from the web server into SPSS. Descriptive statistics were employed for summarizing response characteristics. Odds ratios $(O R)$ with corresponding $95 \%$ confidence intervals $\left(\mathrm{CI}_{95 \%}\right)$ were used to conduct comparisons among categorical variables. The chi-squared test was utilized to assess significance, and a $p$ value $<0.05$ was deemed significant. All statistical analyses were conducted using SPSS software (v. 22.0, Chicago, Illinois, United States).

The total number of radiosurgical cases involved, the number of radiosurgery-related publications and anticipation of performing radiosurgery in future practice could potentially serve as surrogate and actual measures reflecting the perspective of the responding resident on the importance of incorporating radiosurgery training into residency. These variables were dichotomized for statistical comparisons. In terms of total cases, respondents were categorized into having participated in $\leq 5$ or $>5$ cases; with regard to number of publications, respondents were categorized into having $\leq 2$ or $>2$ publications. These values were deemed to represent the lower range of what would represent a potential interest in the field of radiosurgery. Respondents who were uncertain about a future practice involving radiosurgery were not incorporated into this comparison.

\section{Results}

\section{General Participant Characteristics (Table 1)}

Among the 381 individuals surveyed, 119 participated (response rate of $31 \%$ ). One of the 22 surveyed centers was not affiliated with a residency program. The majority of respondents $(102,87 \%)$ were neurosurgeons, while the remaining $17(13 \%)$ were radiation oncologists. Some $40(34 \%)$ were neurosurgery residents, $6(4 \%)$ fellows and $73(62 \%)$ faculty. Among the 73 faculty, $40(55 \%)$ had $>10$ years of experience; 5 of the 22 centers did not have on-site access to radiosurgery. Among the other 17 centers, the linear accelerator (LINAC) was the most common technology (13 centers, 59\%). Gamma Knife was performed at 5 sites (23\%), CyberKnife at 7 (32\%) and spinal radiosurgery at $9(41 \%)$. A combination of these devices was available at 11 sites $(50 \%)$.

As per the responses provided, the ratios of neurosurgeons and radiation oncologists participating in radiosurgical cases were similar to the majority of centers having five or fewer faculty involved (76\% in neurosurgery and $59 \%$ in radiation oncology). 
Most centers performed $>50$ radiosurgery cases annually $(13,76 \%)$, while $6(35 \%)$ reported performing $>150$ cases annually. Brain metastases were the most commonly managed pathology $(59 \%)$, followed by benign tumours (22\%) and malignant primary tumours $(14 \%)$.

Table 1: Characteristics of survey participants and centers

\begin{tabular}{|c|c|}
\hline Variable & $\begin{array}{l}\text { Frequency, } \\
\quad n(\%)\end{array}$ \\
\hline Neurosurgery & $102(87 \%)$ \\
\hline Radiation oncology & $17(13 \%)$ \\
\hline \multicolumn{2}{|l|}{ Level of training } \\
\hline PGY1-4 & $21(18 \%)$ \\
\hline PGY 5-6 & $19(16 \%)$ \\
\hline Fellow & $6(4 \%)$ \\
\hline Faculty ( $<5$ years of practice) & $13(11 \%)$ \\
\hline Faculty (5-10 years of practice) & $20(17 \%)$ \\
\hline Faculty (>10 years of practice) & $40(34 \%)$ \\
\hline \multicolumn{2}{|l|}{ Types of devices available (22 sites)* } \\
\hline Gamma Knife & $5(23 \%)$ \\
\hline CyberKnife & $7(32 \%)$ \\
\hline LINAC & $13(59 \%)$ \\
\hline Spinal radiosurgery & $9(41 \%)$ \\
\hline Combination & $11(50 \%)$ \\
\hline None & $5(23 \%)$ \\
\hline \multicolumn{2}{|l|}{$\begin{array}{l}\text { Number of neurosurgeons practicing radiosurgery at a given center } \\
(17 \text { sites })^{* *}\end{array}$} \\
\hline$<5$ & $13(76 \%)$ \\
\hline 5-10 & $4(24 \%)$ \\
\hline$>10$ & 0 \\
\hline $\begin{array}{l}\text { Number of radiation oncologists practicing radiosurgery at a given } \\
\text { center }(17 \text { sites })^{* *<}<5\end{array}$ & $10(59 \%)$ \\
\hline $5-10$ & $7(41 \%)$ \\
\hline$>10$ & 0 \\
\hline \multicolumn{2}{|l|}{ Estimated annual number of radiosurgery cases at center $(17$ sites $) * *$} \\
\hline$<25$ & $3(18 \%)$ \\
\hline $25-50$ & $(6 \%)$ \\
\hline $51-100$ & $6(35 \%)$ \\
\hline $101-150$ & $1(6 \%)$ \\
\hline$>150$ & $6(35 \%)$ \\
\hline \multicolumn{2}{|l|}{ Top pathological category managed ( $n=51$ respondents) } \\
\hline Brain metastases & $30(59 \%)$ \\
\hline Benign tumors & $11(22 \%)$ \\
\hline Malignant primary tumors & $7(14 \%)$ \\
\hline AVMs & $2(4 \%)$ \\
\hline Trigeminal neuralgia & $1(2 \%)$ \\
\hline Movement disorders & 0 \\
\hline
\end{tabular}

*The response options were not mutually exclusive.

**In cases of inconsistent estimates from the same center, the large categorical number was chosen.

\section{Trainee Perspectives and Involvement in Radiosurgery} (Table 2)

Only 4 residents $(10 \%)$ had $>2$ publications on radiosurgeryrelated topics. More than half $(21,54 \%)$ had yet to participate in a single radiosurgery case, while $11(28 \%)$ had participated in $\leq 5$ cases. On the other end of the spectrum, $5(12 \%)$ had participated in $>20$ cases of radiosurgery. A total of 36 residents $(90 \%)$ believed that knowledge pertaining to radiosurgery was integral to the practice of neurosurgeons, $32(80 \%)$ were of the opinion that the indications for radiosurgery would continue to expand, while $24(60 \%)$ believed that the scope of radiosurgery practice was shared by both neurosurgeons and radiation oncologists.

While $19(43 \%)$ residents/fellows were "comfortable" and 15 (33\%) were "neutral" with regard to the indications for radiosurgery, $21(47 \%)$ were "very uncomfortable" with actually performing radiosurgery (Figure 1 ). The opinion regarding the possibility of incorporating radiosurgery into future practice was relatively even among residents (35\% "yes," 37\% "no," 28\% "not sure"). Five residents (13\%) felt that additional radiosurgery training during residency would have no impact. A notable proportion $(19,46 \%)$, however, felt that it should be incorporated at the expense of time spent on other rotations, followed by $16(41 \%)$

Table 2: Extent of involvement and perspective of neurosurgical residents regarding radiosurgery

\begin{tabular}{l|c|c|c}
\hline & \multicolumn{3}{|c}{ Frequency, $\boldsymbol{n}(\%)$} \\
\hline Variable & All & PGY1-4 & PGY5-6 \\
\hline Number of radiosurgery-related publications $(n=39)$ \\
\hline $0-2$ & $35(90 \%)$ & $19(95 \%)$ & $16(85 \%)$ \\
\hline $3-5$ & $2(5 \%)$ & $1(5 \%)$ & $1(5 \%)$ \\
\hline $6-10$ & $1(2.5 \%)$ & 0 & $1(5 \%)$ \\
\hline$>10$ & $1(2.5 \%)$ & 0 & $1(5 \%)$ \\
\hline Number of radiosurgery cases involved in $(n=39)$ & \\
\hline 0 & $21(54 \%)$ & $3(15 \%)$ & $1(5 \%)$ \\
\hline $1-5$ & $11(28 \%)$ & $11(55 \%)$ & $8(42 \%)$ \\
\hline $6-10$ & $1(3 \%)$ & $5(25 \%)$ & $6(32 \%)$ \\
\hline $11-20$ & $1(3 \%)$ & $1(5 \%)$ & $1(5 \%)$ \\
\hline$>20$ & $5(12 \%)$ & 0 & $3(16 \%)$
\end{tabular}

Knowledge pertaining to radiosurgery integral to practice of neurosurgeon $(n=40)$

\begin{tabular}{l|c|c|c}
\hline Yes & $36(90 \%)$ & $18(85 \%)$ & $18(95 \%)$ \\
\hline No & $3(7.5 \%)$ & $2(10 \%)$ & $1(5 \%)$ \\
\hline Not sure & $1(2.5 \%)$ & $1(5 \%)$ & 0 \\
\hline
\end{tabular}

Domain of radiosurgery falls mainly under scope of $(n=40)$

\begin{tabular}{l|c|c|c}
\hline Neurosurgery & $10(25 \%)$ & $5(24 \%)$ & $5(26 \%)$ \\
\hline Radiation oncology & $5(12.5 \%)$ & $3(14 \%)$ & $2(11 \%)$ \\
\hline Both & $24(60 \%)$ & $12(57 \%)$ & $12(63 \%)$ \\
\hline Not sure & $1(2.5 \%)$ & $1(5 \%)$ & 0 \\
\hline
\end{tabular}

Indications for radiosurgery will likely $(n=40)$

\begin{tabular}{l|c|c|c}
\hline Increase & $32(80 \%)$ & $15(71 \%)$ & $17(89 \%)$ \\
\hline Decrease & $2(5 \%)$ & $1(5 \%)$ & $1(5 \%)$ \\
\hline Not change & $2(5 \%)$ & $2(10 \%)$ & 0 \\
\hline Not sure & $4(10 \%)$ & $3(14 \%)$ & $1(5 \%)$ \\
\hline
\end{tabular}




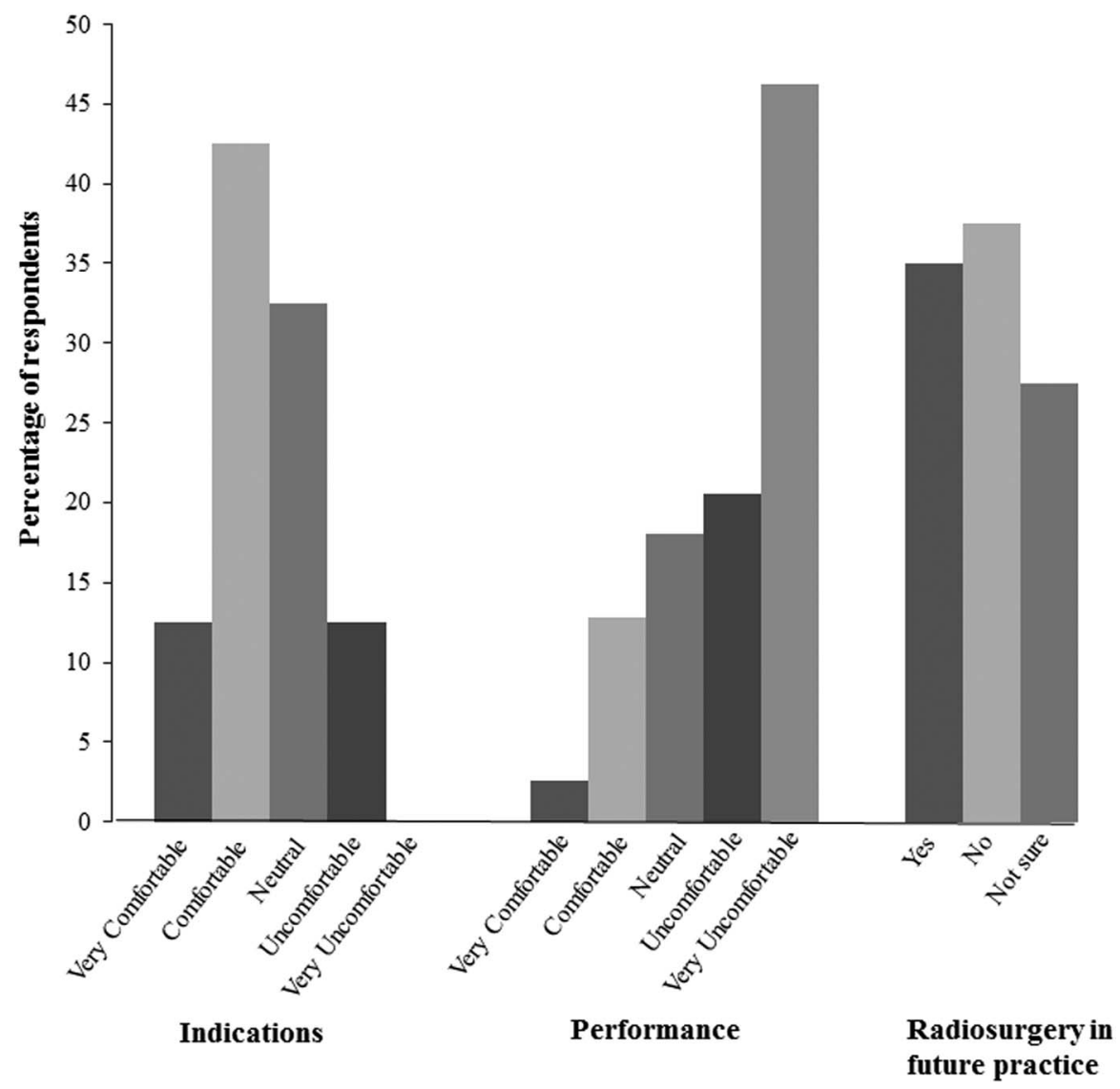

Figure 1: Residents' current and future perspectives on the practice of radiosurgery.

who felt that the current time required for other skill-sets would not permit this. The odds of residents believing that sacrificing time on other rotations in favour of radiosurgery training could be beneficial was higher than for faculty (neurosurgeons and radiation oncologists), and this relative difference approached significance $\left(O R=2.1, C I_{95 \%}=0.96-4.6, p=0.06\right)$.

\section{Faculty Perspectives on Formal Training}

Among faculty respondents, none were of the opinion that "no training" would be beneficial. The majority $(42,57 \%)$ of faculty respondents believed that incorporation of radiosurgery training would be beneficial but likely impractical, while 26 (35\%) believed that such training was beneficial and must be incorporated into training, and $5(7 \%)$ felt that incorporation of radiosurgery training would have no impact (Figure 2). Neurosurgery faculty were more likely to be in favour of mandating incorporation of radiosurgery training, compared to radiation oncology faculty, although this was not statistically significant $(O R=1.5$, $\left.C I_{95 \%}=0.4-5.8, \mathrm{NS}\right)$.

\section{Correlation of Current Resident Involvement in Radiosurgery with Perspective}

Among residents participating in $\leq 5$ radiosurgery cases $(n=32), 11(33 \%)$ were in favour of incorporating radiosurgery at the expense of other rotations, while among those with $>5$ radiosurgery cases $(n=7), 4(56 \%)$ held this opinion. While the relative percentages were potentially reflective of the true differences in perspective, the sample was small and the odds not significantly different $\left(O R=0.4, C I_{95 \%}=0.1-1.7, \mathrm{NS}\right)$. The odds of residents who anticipated a future practice involving radiosurgery being in favour of sacrificing time on other rotations ( 9 of 17, 53\%) were higher than for those who did not anticipate such a practice ( 4 of $18,22 \%$ ), and this difference did approach significance $\left(O R=3.9, C I_{95 \%}=0.9-17, p=0.06\right)$.

\section{Optimal Training Duration}

Among the 39 residents providing input, none were of the opinion that "no training" would be beneficial. The majority were of the opinion that 1 month $(12,31 \%)$ or 1 to 3 months $(17,44 \%)$ would be sufficient time for in-program residency training. Only $6(15 \%)$ residents believed that training should be obtained only during fellowship years (Figure 3). Among the 19 residents who had participated in at least one radiosurgery case, the optimal training duration was chosen as "1 month" by 6 (32\%), "1-3 months" by 8 (42\%) and " $3-6$ months" by $3(16 \%)$, and in the form of a formal fellowship by $2(10 \%)$. Although $59 \%(56 / 73)$ of faculty felt that less than 3 months would suffice, $30 \%(22 / 73)$ supported the concept that this should only be pursued as part of dedicated fellowship training.

\section{Qualitative Input}

Faculty responses ranged from "not necessary for most residents," "can pursue training via elective/infolded or other fellowship if interested" and "reasonable exposure already 


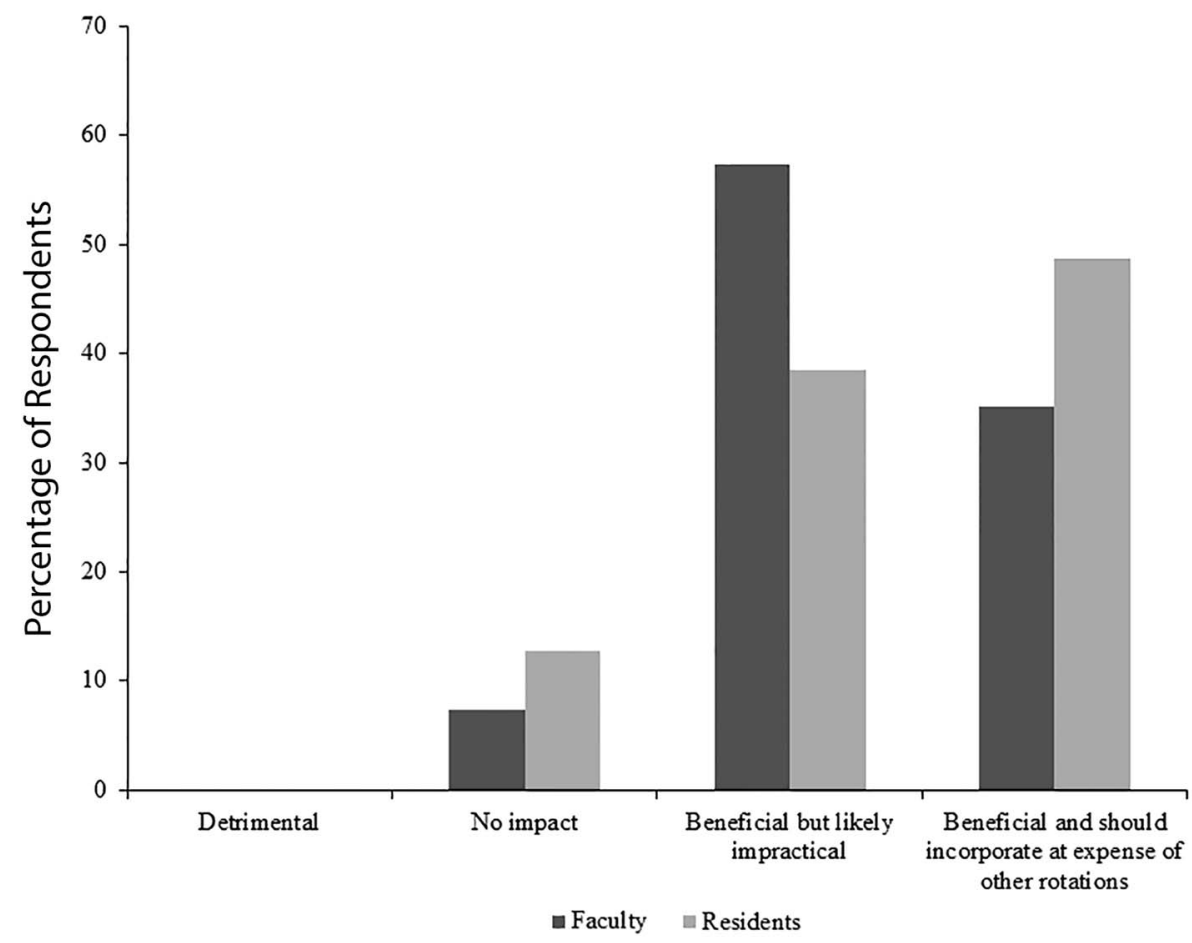

Figure 2: Comparison of the relative views of residents and faculty regarding the feasibility of a mandatory radiosurgery rotation.

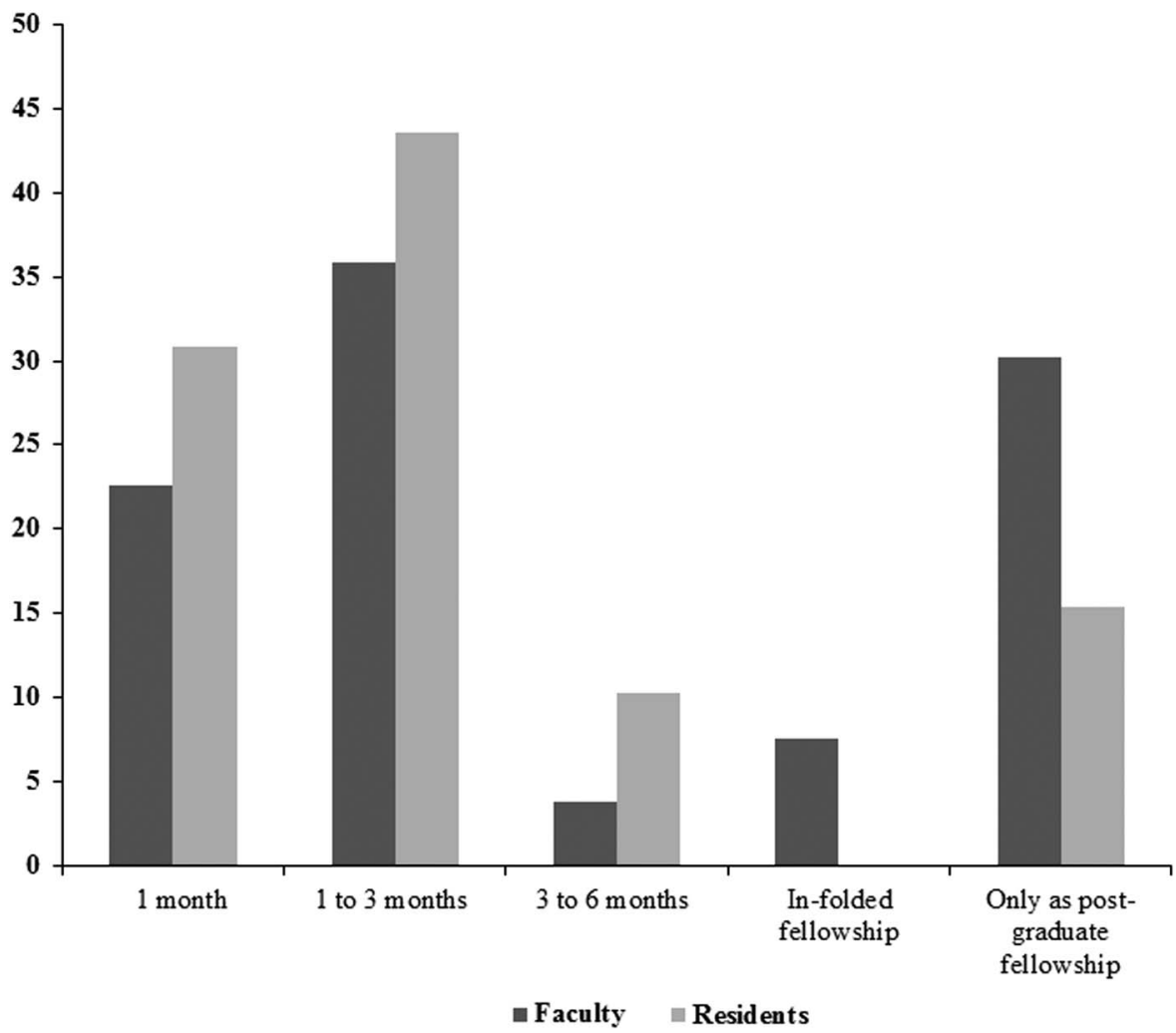

Figure 3: Perspectives on the optimal format and duration of training according to faculty and residents. 
through SRS weekly rounds/patient referrals/regular practice in our institution" to "I would fully support a mandatory neurosurgical and radiation oncology residency rotations at our facility," "a short rotation would suffice to teach the principles of radiosurgery; it would not take much time away from other things" and "I expect that SRS is likely to expand considerably in the future; it should be regarded as complementary to a multidisciplinary neuro-oncology program." One respondent suggested that they "would not offer it as a dedicated block but make it part of a competency-based requirement with participation in a minimum number of cases (20, etc.) during training."

Resident comments included the following: "ideally, should be an optional elective within the six-year curriculum, similar to endovascular and other subspecialty training"; "some exposure would be beneficial during residency to understand the treatment, indications and implications; one can then pursue further if interested"; and "not as a set rotation but as part of a competencybased expectation of participation in a number of cases."

\section{DISCUSSION}

In this study, a cross-sectional survey was conducted to assess the current landscape of radiosurgery practice across Canada and to assess the perspectives of faculty and trainees with respect to the necessity and feasibility of dedicated training in radiosurgery for neurosurgical residents. A large proportion of residents recognized the importance of radiosurgery to neurosurgical practice, and while the majority were comfortable with the theory of and indications for radiosurgery, they were not comfortable with performing it. Both faculty and residents for the most part agreed that some form of training would be necessary, though the practicality of dedicated training was a concern. Although direct case involvement and number of radiosurgery-related publications were for the most part low, this was not reflective of the extent of resident interest. They were more likely to believe that time dedicated to radiosurgery training, at the expense of time on other rotations would be beneficial. This is likely a reflection of the recognition of the expanding indications for radiosurgery.

More than a third of Canadian centers surveyed reported a relatively high volume of radiosurgical cases ( $>150$ yearly). Although no comparative data from prior time periods are available, this is a reflection of the expanding indications for radiosurgery and its acceptance as an effective modality. ${ }^{10,17}$ According to a comparison of annual billing codes submitted to Medicare/Medicaid services in the United States, the number of radiosurgery cases surpassed the number of craniotomy cases for tumours (excluding meningiomas) around the year 2003. ${ }^{10}$

At the outset of the development of radiosurgery, neurosurgeons were primarily involved in the management of benign solitary lesions while multiple metastatic lesions were primarily the domain of radiation oncologists. ${ }^{18-20}$ In 2015 , radiosurgery was the commonest management strategy for the most prevalent brain tumour: cerebral metastases. This is indeed supported by class II evidence regarding the survival advantage of radiosurgery boost compared to whole-brain radiotherapy alone, ${ }^{20}$ survival rates comparable to microsurgery ${ }^{21,22}$ and increased effectiveness for lesions recurring following whole-brain radiotherapy. ${ }^{23}$ The outpatient nature of radiosurgery confers a costeffectiveness advantage over microsurgery as well. In addition, the role of radiosurgery for vascular lesions (e.g., arteriovenous malformations ${ }^{24}$ ); benign tumours (e.g., vestibular schwannomas, ${ }^{25}$ meningiomas $^{2}$ and pituitary adenomas ${ }^{26,27}$ ); and trigeminal neuralgia ${ }^{4}$ has also been validated. Indeed, there is peer-reviewed literature to support the value of radiosurgery on almost all adult intracranial tumours.

In recognition of the expanding role of radiosurgery in the management of patients with a diverse set of pathologies, the radiation oncology associations of Canada (CARO) and America (ASTRO) have taken the lead in developing documents that define the scope of practice for their specialty. ${ }^{28,29}$ Collectively, these organizations have recognized that the training of radiation oncologists should include developing expertise in the science of radiation biology and its clinical relevance, providing an understanding of the techniques for the delivery of radiation, and enhancing familiarity with the regulatory and administrative aspects of radiosurgery, as well as involving trainees in patient care from initial consultation to follow-up. In Canada, a formal rotation pertaining to "neurologic cancers" is an RCPSC requirement for radiation oncology residents. ${ }^{16}$ In the United States, the ACGME requires that residents participate in a minimum of 20 intracranial radiosurgery cases. ${ }^{30}$ As equal partners and key contributing members to the practice of radiosurgery, a similar scope of practice definition by the neurosurgical specialty is also necessary. Areas of focus would include a comprehensive understanding of the indications, contraindications and expected outcomes associated with radiosurgery. In addition, consideration of dosimetric parameters, potential complications and management of these complications is paramount. ${ }^{31}$ Unfortunately, Canadian neurosurgical residents are currently not formally trained in radiosurgery and many feel "very uncomfortable" with its techniques.

The sentiment of Canadian neurosurgical residents with regard to the divide between interest and actual training is not one that is solely found in Canada. In the setting of a national neurosurgery resident-oriented radiosurgery course in 2010, a third of surveyed participants felt "very uncomfortable" with the techniques required for intracranial radiosurgery. ${ }^{31}$ Furthermore, a Council of State Neurosurgical Societies survey of recent American neurosurgical graduates in 2008 identified radiosurgery as one of the inadequately addressed skill-sets. ${ }^{32}$ This is not surprising given that the proportion of radiosurgery cases with neurosurgery resident participation in America at the time was as low as 5\%. ${ }^{10}$

Recognizing this disparity, the ACGME recently mandated the formal involvement of American neurosurgical residents in a minimum of 10 radiosurgery cases during training. This format appears to be a compromise in response to the need expressed by residents, the imposed duty-hour restrictions and the need for dedication of time to other essential skill-sets. ${ }^{33-35}$ Although this is an improvement, the evidence with regard to the effectiveness of this approach is not clear. The likelihood that 10 cases would encompass the full breadth and diversity of radiosurgical cases is low. As one of the pioneering centers in radiosurgery training, the University of Pittsburgh Medical Center has established formal resident training rotations spanning 3 to 4 months in duration. ${ }^{36}$ Alternatively, short-term training courses can also be offered to interested residents, without sacrificing much time for other skill-sets. ${ }^{31}$ Similar approaches can be potentially implemented in Canadian neurosurgery training programs as well. However, such factors as the shorter duration of training (6 vs. 7 years at most centers) and the current absence of an established 
competency-based curriculum for neurosurgery residents in Canada must be considered.

The majority of Canadian residents supported the option of one to three months of dedicated training in radiosurgery. Although this proportion for faculty was lower, they were supportive of this option as well. Some participants, both residents and faculty, commented that a required participation in a set number of cases and/or as part of a competency-based curriculum would suffice. These latter options were not offered on our survey, and it would therefore be difficult to draw conclusions with regard to their popularity among participants. An alternative option would be the possibility of longitudinal involvement in radiosurgery cases, as part of the routine care of neurosurgical patients, through participation in outpatient clinics, multidisciplinary case discussions and actual radiosurgery cases. Based on the number of publications to date on this option, the evidence is limited, leaving uncertainty with respect to the ideal structure and approach to incorporation of radiosurgery training. However, the results of this survey suggest that a substantial proportion of residents and faculty are interested in exploring the topic further. Given the recent interest in shifting toward competency-based learning in Canada, the topic of radiosurgery needs to be closely examined, and potential options and strategies must be discussed.

\section{LIMITATIONS}

The possibility of subjective interpretation of questions and recall bias cannot be ruled out. Although this limits the accuracy of the cross-sectional statistics for radiosurgery across Canada, the data do provide a general understanding of the current landscape of radiosurgery across the nation. As with most other surveys, it is possible that the full breadth of possible options for each query was not offered, potentially limiting accuracy. In addition, the perspective of respondents could have varied depending on whether a center already implemented a competency-based curriculum, and this was not queried in our survey. While not all participants provided comments, we were able to gain insight into other potential options based on the additional free-text responses provided by some participants. The decision to survey only radiation oncologists involved in an academic practice could have also contributed to the relatively lower response rate among this cohort. Our $31 \%$ response rate can be a potential source of bias, given the possibility of a systematic difference between the opinions held by responders compared with non-responders. ${ }^{37}$ This would especially be relevant to the perspective offered by residents, among whom the participation rate was lower. The response rates could have perhaps been improved upon by additional supplementary methods, such as paper-based surveys administered during resident-focused courses, as have been previously conducted. ${ }^{31}$ However, other survey studies pertaining to neurosurgeons, providing valuable insights, have also been based on similar response rates. ${ }^{32,33}$ Furthermore, a relatively large population (381 individuals) were surveyed, which can potentially help reduce the imprecision associated with our results. ${ }^{38}$ In an effort to maintain anonymity, we were not able to assess for systematic differences between responders and non-responders. However, assuming that a systematic variation was indeed a factor, approximately one-third of Canadian residents and faculty surveyed had an interest in radiosurgery and its potential incorporation into neurosurgical residency training. This suggests that the concept merits consideration by the RCPSC.

\section{Conclusions}

Both neurosurgeons and radiation oncologists play a pivotal role in the safe and effective management of patients undergoing radiosurgical procedures. In accepting this responsibility as neurosurgeons, a systematic approach toward training is necessary, even if a future direct involvement in radiosurgery is not anticipated, in order to ensure that patient care is delivered in an evidence-based, safe and effective manner. Despite this, the majority of participating Canadian neurosurgery residents feels inadequately trained. Thus, the concept of incorporating radiosurgery training into the Canadian neurosurgical curriculum needs consideration. While the ideal model is not clear, potential strategies must be explored.

\section{Disclosures}

The authors have no relevant conflicts to disclose.

\section{SUPPLEMENTARY MATERIAL}

To view supplementary material for this article, please visit http://dx.doi.org/10.1017/cjn.2016.314

\section{REFERENCES}

1. Kondziolka D, Flickinger JC, Dade Lunsford L. Clinical research in stereotactic radiosurgery: lessons learned from over 10,000 cases. Neurol Res. 2011;33(8):792-802.

2. Kondziolka D, Patel AD, Kano H, Flickinger JC, Lunsford LD. Long-term outcomes after Gamma Knife radiosurgery for meningiomas. Am J Clin Oncol. 2014, Epub ahead of print.

3. Chen CJ, Lee CC, Ding D, Starke RM, Chivukula S, Yen CP, et al. Stereotactic radiosurgery for intracranial dural arteriovenous fistulas: a systematic review. J Neurosurg. 2015;122(2):353-62. Epub ahead of print Dec 5. Available at: http://thejns.org/doi/pdf/ 10.3171/2014.10.JNS14871.

4. Kano H, Kondziolka D, Yang HC, Zorro O, Lobato-Polo J, Flannery TJ, et al. Outcome predictors after Gamma Knife radiosurgery for recurrent trigeminal neuralgia. Neurosurgery. 2010;67(6):1637-44; discussion 1644-5.

5. Kim JH, Jung HH, Chang JH, Chang JW, Park YG, Chang WS. Gamma Knife surgery for intracranial chordoma and chondrosarcoma: radiosurgical perspectives and treatment outcomes. J Neurosurg. 2014;121(Suppl):188-97.

6. Sheehan JP, Lee CC. Stereotactic radiosurgery for recurrent highgrade gliomas. World Neurosurg. 2014;82(5):e593-5; Epub ahead of print Jun 19 .

7. Lunsford LD, Khan AA, Niranjan A, Kano H, Flickinger JC, Kondziolka D. Stereotactic radiosurgery for symptomatic solitary cerebral cavernous malformations considered high risk for resection. J Neurosurg. 2010;113(1):23-9.

8. Bertolini F, Spallanzani A, Fontana A, Depenni R, Luppi G. Brain metastases: an overview. CNS Oncol. 2015;4(1):37-46.

9. Sheehan JP, Jagannathan J. Review of spinal radiosurgery: a minimally invasive approach for the treatment of spinal and paraspinal metastases. Neurosurg Focus. 2008;25(2):E18. Available at: http://thejns.org/doi/pdf/10.3171/FOC/2008/25/8/E18.

10. Lunsford LD, Chiang V, Adler JR, Sheehan J, Friedman W, Kondziolka D. A recommendation for training in stereotactic radiosurgery for US neurosurgery residents. J Neurosurg. 2012: (117 Suppl):2-4.

11. Accreditation Council for Graduate Medical Education (ACGME). Milestones. 2016. Available at: http://www.acgme.org/ acgmeweb/tabid/430/ProgramandInstitutionalAccreditation/Next AccreditationSystem/Milestones.aspx.

12. Mansouri A, Aldakkan A, Badhiwala JH, Taslimi S, Kondziolka D. A practical methodological approach towards identifying core competencies in medical education based on literature trends: a feasibility study based on vestibular schwannoma science. 
Neurosurgery. 2015;77(4):594-602; discussion 602-3. Available at: http://journals.lww.com/neurosurgery/_layouts/15/oaks.journals. mobile/articleviewer.aspx ?year $=2015 \&$ issue $=10000 \&$ article $=$ 00021.

13. Grussing PG. Education and practice: is competency-based education closing the gap? Am J Pharm Educ. 1984;48(2): 117-24.

14. Dickerman RD, McConathy WJ, Pearl NA, Stevens QE, Cohen A, Schneider SJ. Pediatric cranial fixation: a survey of pediatric neurosurgeons. J Craniofac Surg. 2002;13(6):769-71.

15. Graber MA, Hartz A, James P, Nugent A, Green MD. An alternative method of determining standard of care in alleged cases of malpractice. J Am Board Family Prac. 2005;18(6):453-8.

16. Royal College of Physicians and Surgeons of Canada. Specialty Training Requirements in Radiation Oncology. 2014. Available at: http://www.royalcollege.ca/portal/page/portal/rc/credentials/ accreditation/arps/specialty/rad_oncology.

17. Kondziolka D, Lunsford LD, Loeffler JS, Friedman WA. Radiosurgery and radiotherapy: observations and clarifications. J Neurosurg. 2004;101(4):585-9.

18. Patchell RA, Tibbs PA, Walsh JW, Dempsey RJ, Maruyama Y, Kryscio RJ, et al. A randomized trial of surgery in the treatment of single metastases to the brain. New Engl J Med. 1990;322(8):494500; Available at http://www.nejm.org/doi/full/10.1056/NEJM 199002223220802\#t=articleTop.

19. Muacevic A, Wowra B, Siefert A, Tonn JC, Steiger HJ, Kreth FW. Microsurgery plus whole brain irradiation versus Gamma Knife surgery alone for treatment of single metastases to the brain: a randomized controlled multicentre phase III trial. J Neurooncol. 2008;87(3):299-307; Epub ahead of print Dec 22, 2007.

20. Andrews DW, Scott CB, Sperduto PW, Flanders AE, Gaspar LE, Schell MC, et al. Whole brain radiation therapy with or without stereotactic radiosurgery boost for patients with one to three brain metastases: phase III results of the RTOG 9508 randomised trial. Lancet. 2004;363(9422):1665-72.

21. Soffietti R, Costanza A, Laguzzi E, Nobile M, Ruda R. Radiotherapy and chemotherapy of brain metastases. J Neurooncol. 2005; 75(1):31-42.

22. Rades D, Kueter JD, Veninga T, Gliemroth J, Schild SE. Whole brain radiotherapy plus stereotactic radiosurgery (WBRT + SRS) versus surgery plus whole brain radiotherapy $(\mathrm{OP}+\mathrm{WBRT})$ for 1-3 brain metastases: results of a matched pair analysis. Eur J Cancer. 2009;45(3):400-4; Epub ahead of print Dec 4, 2008.

23. Shaw E, Scott C, Souhami L, Dinapoli R, Kline R, Loeffler J, et al. Single dose radiosurgical treatment of recurrent previously irradiated primary brain tumors and brain metastases: final report of RTOG protocol 90-05. Int J Radiat Oncol Biol Phys. 2000; 47(2):291-8.

24. Abla AA, Rutledge WC, Seymour ZA, Guo D, Kim H, Gupta N, et al. A treatment paradigm for high-grade brain arteriovenous malformations: volume-staged radiosurgical downgrading followed by microsurgical resection. J Neurosurg. 2015;122 (2):419-32; Epub ahead of print Nov 28, 2014. Available at: http://thejns.org/doi/pdf/10.3171/2014.10.JNS1424.

25. Yang HC, Kano H, Awan NR, Lunsford LD, Niranjan A, Flickinger JC, et al. Gamma Knife radiosurgery for larger-volume vestibular schwannomas: clinical article. J Neurosurg. 2013:(119 Suppl):801-7.
26. Park KJ, Kano H, Parry PV, Niranjan A, Flickinger JC, Lunsford LD, et al. Long-term outcomes after Gamma Knife stereotactic radiosurgery for nonfunctional pituitary adenomas. Neurosurgery. 2011;69(6):1188-99.

27. Sheehan JP, Starke RM, Mathieu D, Young B, Sneed PK, Chiang VL, et al. Gamma Knife radiosurgery for the management of nonfunctioning pituitary adenomas: a multicenter study. J Neurosurg. 2013;119(2):446-56; Epub ahead of print Apr 26. Available at http://thejns.org/doi/pdf/10.3171/2013.3. JNS12766.

28. SCOPE Steering Committee and Subcommittees. Report of the American Society for Therapeutic Radiology and Oncology Working Group on the scope of radiation oncology (SCOPE). Int J Radiat Oncol Biol Phys. 2002;54(2):317-26.

29. Roberge D, Menard C, Bauman G, Chan A, Mulroy L, Sahgal A, et al. Radiosurgery scope of practice in Canada: a report of the Canadian Association of Radiation Oncology (CARO) Radiosurgery Advisory Committee. Radiother Oncol. 2010;95(1): 122-8; Epub ahead of print Feb 17.

30. Accreditation Council for Graduate Medical Education (ACGME). ACGME Program Requirements for Graduate Medical Education in Radiation Oncology. 2015. Available at: https://www.umc.edu/ uploadedFiles/UMCedu/Content/Education/Schools/Medicine/ Clinical_Science/Radiation_Oncology/Academics/ACGMER equirementsRadOnc.pdf.

31. Sheehan JP. Resident perceptions of radiosurgical training and the effect of a focused resident training seminar. J Neurosurg. 2010;113(1):59-63.

32. Mazzola CA, Lobel DA, Krishnamurthy S, Bloomgarden GM, Benzil DL. Efficacy of neurosurgery resident education in the new millennium: the 2008 Council of State Neurosurgical Societies post-residency survey results. Neurosurgery. 2010;67(2):225-32; discussion 232-3.

33. Cohen-Gadol AA, Piepgras DG, Krishnamurthy S, Fessler RD. Resident duty hours reform: results of a national survey of the program directors and residents in neurosurgery training programs. Neurosurgery. 2005;56(2):398-403.

34. Grady MS, Batjer HH, Dacey RG. Resident duty hour regulation and patient safety: establishing a balance between concerns about resident fatigue and adequate training in neurosurgery. J Neurosurg. 2009;110(5):828-36; Available at http://thejns.org/doi/pdf/ 10.3171/2009.2.JNS081583.

35. Jagannathan J, Vates GE, Pouratian N, Sheehan JP, Patrie J, Grady MS, et al. Impact of the Accreditation Council for Graduate Medical Education work-hour regulations on neurosurgical resident education and productivity. J Neurosurg. 2009;110 (5):820-7; Available at http://thejns.org/doi/pdf/10.3171/2009.2. JNS081446.

36. Harrison G, Grandhi R, Monaco EA 3rd, Niranjan A, Lunsford LD. The evolution of training in brain stereotactic radiosurgery: a growing part of intracranial neurosurgery. World Neurosurg. 2014;82(3-4):292-7. Epub ahead of print May 15.

37. Altman DG, Bland JM. Missing data. BMJ. 2007;334(7590): 424. Available at http://www.ncbi.nlm.nih.gov/pmc/articles/ PMC1804157/.

38. Evans SJ. Good surveys guide. BMJ. 1991;302(6772):302-3; Available at http://www.ncbi.nlm.nih.gov/pmc/articles/PMC1669002/. 